\title{
Article \\ Fatty Acid Profiles of Selected Microalgae Used as Live Feeds for Shrimp Postlarvae in Vietnam
}

\author{
Thao Duc Mai ${ }^{1}$, Kim Jye Lee-Chang ${ }^{2, *}$ C , Ian D. Jameson ${ }^{3}$, Tung Hoang ${ }^{4}$, Ngoc Bao Anh Cai ${ }^{5}$ \\ and Hung Quoc Pham ${ }^{1}$ (I) \\ 1 Institute of Aquaculture, Nha Trang University, Nha Trang 57000, Vietnam; thaomd@ntu.edu.vn (T.D.M.); \\ hungpq@ntu.edu.vn (H.Q.P.) \\ 2 CSIRO Oceans \& Atmosphere, Hobart, TAS 7000, Australia \\ 3 CSIRO National Collections and Marine Infrastructure, Hobart, TAS 7000, Australia; Ian.Jameson@csiro.au \\ 4 CSIRO Agriculture \& Food, Woorim, QLD 4507, Australia; Tung.Hoang@csiro.au \\ 5 Minh Phu Seafood Corporation, Cà Mau 98000, Vietnam; bao_cai@minhphu.com \\ * Correspondence: Kim.Leechang@csiro.au; Tel.: +61-3-6232-5224
}

Citation: Mai, T.D.; Lee-Chang, K.J.; Jameson, I.D.; Hoang, T.; Cai, N.B.A.; Pham, H.Q. Fatty Acid Profiles of Selected Microalgae Used as Live Feeds for Shrimp Postlarvae in Vietnam. Aquac. J. 2021, 1, 26-38. https://doi.org/10.3390/aquacj1010004

Academic Editors: Aires Oliva-Teles and Wilson Wasielesky

Received: 25 August 2021

Accepted: 19 October 2021

Published: 22 October 2021

Publisher's Note: MDPI stays neutral with regard to jurisdictional claims in published maps and institutional affiliations.

Copyright: (c) 2021 by the authors. Licensee MDPI, Basel, Switzerland. This article is an open access article distributed under the terms and conditions of the Creative Commons Attribution (CC BY) license (https:/ / creativecommons.org/licenses/by/ $4.0 /)$.

\begin{abstract}
The importance of microalgal lipids for the survival and growth of shrimp postlarvae has been recognized in a range of studies. Microalgae with fast growth rates and high levels of polyunsaturated fatty acids (PUFA) are considered vital to maximise production and minimise cost in shrimp larviculture. The lipid content and fatty acid composition of microalgae used in shrimp production varies substantially between the algal classes and species being used in Vietnam. This study aims to characterise microalgal lipid and fatty acid (FA) profiles and evaluate the most promising species under growth conditions that are most suitable for shrimp aquaculture. Here, we report that the highest lipid contents were obtained in the Haptophyta microalgae, Tisochrysis lutea and Isochrysis galbana, at 90.3 and $61.1 \mathrm{mg} / \mathrm{g}$, respectively. In contrast, two of the most popular diatom species being used for shrimp larval cultivation in Vietnam, Thalassiosira pseudonana and T. weissflogii, displayed the lowest lipid contents at $16.1 \mathrm{mg} / \mathrm{g}$. Other microalgal species examined showed lipid contents ranging from 28.6 to $55 \mathrm{mg} / \mathrm{g}$. Eicosapentaenoic acid (EPA, 20:5 53 ) ranged from 0.6 to $29.9 \%$ across the species, with docosahexaenoic acid (DHA, 22:6w3) present at 0.01 to $11.1 \%$; the two omega ( $\omega$ )-3 long-chain (LC, $\geq$ C20) LC-PUFA varied between the microalgae groups. Polar lipids were the main lipid class, ranging from 87.2 to $97.3 \%$ of total lipids, and triacylglycerol was detected in the range of 0.01 to $2.5 \%$. Saturated fatty acids (SFA) and monounsaturated fatty acids (MUFA) increased and PUFA decreased with increasing growth temperatures. This study demonstrated the differences in the lipid contents and FA profiles across 10 microalgal species and the effect of the higher temperature growing conditions encountered in Vietnam.
\end{abstract}

Keywords: phytoplankton; polyunsaturated fatty acids; live feeds

\section{Introduction}

Microalgae are microscopic organisms that can be found in all kinds of terrestrial, marine, and freshwater environments and are responsible for approximately half of global primary production [1,2]. They are known as a widely diverse group of primary photosynthetic microorganisms that include either eukaryotes (Rhodophytes, Chlorophytes, and Chromophytes) or prokaryotes (Cyanobacteria). Many microalgae are also characterized by their fast growth, flexibility, and adaptability to various environmental conditions. Being such a rich source of lipids, essential amino acids, pigments, carbohydrates, proteins, vitamins, and other bioactive compounds in cells, microalgae can be widely applied in several industries such as human food, aqua- and livestock feed, pharmaceuticals, and cosmetics [3-5].

The biomass of microalgae can rapidly double in periods as short as several hours [6-8]. Generally, the percentage of lipid content per dry weight of most microalgae is in the range 
of 1 to $50 \%$, and Chlorophyta displays the most abundant number of species with a wide range of lipid concentrations reported in various studies $[7,9,10]$. Moreover, it is well known that one of the most significant nutritional values of certain microalgae lies in their rich source of the long-chain (LC, $\geq$ C20), LC-PUFA-eicosapentaenoic acid (EPA), and docosahexaenoic acid (DHA). The $\omega-3,6$, and 9 FAs also appear to be key for many applications $[9,11,12]$. The PUFA content reaches an extremely high level in some microalgal species such as Rhodomonas sp. 56-72\% total fatty acids (TFA).

Being a rich source of lipids, as well as containing diverse fatty acid compositions, the use of microalgae as a live feed becomes a crucial factor in regulating the growth, development, and survival of aquatic animals. Studies have shown that many physiological disorders and morphological abnormalities of visual and neural tissues in many fishes and crustacean larvae have occurred due to deficiencies in essential fatty acids, including linoleic acid, linolenic acid, DHA, and EPA $[13,14]$. In addition to the high lipid content in cells, the essential fatty acid composition of the diet also has a considerable positive effect on diet digestibility in aquatic animals, especially in the early, relatively weak larval stages, which are highly sensitive and have an underdeveloped digestive systems [15-18]. The formation and development of membranes in aquatic larvae requires optimal phospholipids in their feed. The triacylglycerol content in microalgal lipid provides a major energy source for aquatic larvae during key periods of development, in osmoregulation and in protection against environmental stresses. Sterols can be found in many microalgae that are of further importance as hormone precursors $[15,19,20]$. The optimization of microalgae live feed is therefore one of the most important nutritional concerns in shrimp larval cultivation.

Shrimp seedstock production in Vietnam, mostly white leg shrimp, has had a remarkable increase in the last decade, with annual production of more than 2000 hatcheries estimated at around 120-140 billion postlarvae in 2018 to 2019. In the process of shrimp larviculture in Vietnam, microalgae have been used as the feedstock. The marine diatom Thalassiosira weissflogii is often used for larviculture in large-scale hatcheries. Smaller hatcheries either purchase live diatoms or use dried Spirulina (Arthrospira sp) as feeds due to the lack of availability and high production cost of alternative live microalgae [21]. Despite the rising demand for high-quality microalgae as live feed, several challenges, including the high capital cost of large-scale cultivation systems and a lack of understanding of microalgal species or strains, have made commercial production economically unfeasible. This study aims to provide the lipid content and FA profiles of key microalgal species available to the expanding Vietnamese shrimp industry, including when cultured under conditions suitable for use by the local industry, as an important first step to characterize and select specific species or strains. Subsequent research and development will aim to then achieve an efficient and effective cultivation system for shrimp larval production in Vietnam $[11,22,23]$.

\section{Materials and Methods}

Microalgal species used in this study are sourced from the Australian National Algae Culture Collection (http:/ / www.csiro.au / ANACC, accessed on 2 July 2021) with details shown in Table 1 and Figure A1. Each 60-mL culture was inoculated with $4 \mathrm{~mL}$ of starter culture in 100-mL Erlenmeyer flasks. All cultures were grown in $\mathrm{f} / 2$ medium. The flasks were incubated for 14 days in controlled environment rooms, with light provided by cool white fluorescent tubes $(80-100 \mu \mathrm{mol}$ photonsm $-2 \mathrm{~s}-1 \mathrm{PAR})$ under a 12:12 light dark cycle at 3 different temperatures: $20^{\circ} \mathrm{C}, 25^{\circ} \mathrm{C}$, and $30^{\circ} \mathrm{C}$. Light microscope images were taken on a ZeissAxioplan microscope using $\times 1000$ differential interference contrast (DIC) optics and a Zeiss Axiocam HRc model digital camera. The data for the 10 species ( $\mathrm{n}=2$ analyses) at the end of the 14-day screening trial are presented in this paper.

Samples $(10 \mathrm{mg})$ were extracted quantitatively by the modified dichloromethane (DCM)-methanol (MeOH)-water Bligh and Dyer (1959) method [24]. After phase separation, the lipids were recovered in the lower DCM layer, and a second extraction was performed to maximise lipid recovery. Solvents were removed in vacuo. Lipid recovery 
was determined gravimetrically. An aliquot of the total lipid was made up to a known volume for thin-layer chromatography-flame ionization detection (TLC-FID) analysis.

Table 1. Microalgal species investigated in this study; CS number refers to strains deposited in the Australian National Algae Culture Collection.

\begin{tabular}{ccccc}
\hline & Genus Plus Species & Class & Class Vernacular & Source Country \\
\hline CS-5 & Cylindrotheca closterium & Bacillariophyceae & Diatom & Australia \\
CS-29 & Phaeodactylum tricornutum & Bacillariophyceae & Diatom & United Kingdom \\
CS-176 & Chaetoceros muelleri & Coscinodiscophyceae & Diatom & USA \\
CS-178 & Chaetoceros calcitrans & Coscinodiscophyceae & Diatom & Japan \\
CS-252 & Skeletonema pseudocostatum & Coscinodiscophyceae & Diatom & Australia \\
CS-173 & Thalassiosira pseudonana & Coscinodiscophyceae & Diatom & USA \\
CS-871 & Thalassiosira weissflogii & Coscinodiscophyceae & Diatom & USA \\
CS-186 & Isochrysis galbana & Coccolothophyceae & Prymnesiophyte & USA \\
CS-177 & Tisochrysis lutea & Coccolothophyceae & Prymnesiophyte & Tahiti \\
CS-179 & Nannochloropsis oceanica & Eustigmaophyceae & Eustigmatophycea & Japan \\
\hline
\end{tabular}

\subsection{Lipid Class Composition}

Aliquots of each of the diluted oils were analysed using an Iatroscan MK V TLCFID analyser (Iatron Laboratories, Japan) to determine the abundance of individual lipid classes. Samples were applied to silica gel SIII chromarods $(5 \mu \mathrm{m}$ particle size $)$ using $1-\mu \mathrm{L}$ disposable micro pipettes. The chromarods were developed in a glass tank lined with preextracted filter paper. The solvent system used for the lipid separation was hexane-diethyl ether-acetic acid (60:17:0.2 $v / v)$, a mobile phase providing good resolution between nonpolar compounds such as wax ester, triacylglycerol, and free fatty acid. After development (30 $\mathrm{min})$, the chromarods were oven dried $(8 \mathrm{~min})$ and analysed immediately to minimise adsorption of atmospheric contaminants. Data presented are for qualitative percentages of individual lipid classes. Iatroscan results have been previously shown to be reproducible to $\pm 10 \%$ or better [25].

\subsection{Methylation and Analysis of Fatty Acid Methyl Esters (FAME)}

The extracted lipids were transesterified with methanol/dichloromethane/ $\mathrm{HCl}$ (10:1:1 $v / v / v$ ) to convert fatty acids from the complex lipids into FAME, as described in detail previously [26]. A known volume of dichloromethane containing the internal injection standard (19:0 FAME) was then added to each sample vial. Individual fatty acids are expressed as a percentage of the total fatty acids (TFA). Gas chromatography (GC) was used to identify and quantify the fatty acids and was performed on an Agilent Technologies 7890A GC (Palo Alto, CA, USA) equipped with a nonpolar Equity-1 ${ }^{\mathrm{TM}}$ fused silica capillary column (15 $\mathrm{m} \times 0.1 \mathrm{~mm}$ i.d., $0.1 \mathrm{~mm}$ film thickness), flame ionization detector, and split/splitless injector. Samples were injected in splitless mode at an oven temperature of $120{ }^{\circ} \mathrm{C}$, and after injection, the oven temperature was increased to $270{ }^{\circ} \mathrm{C}$ at $10{ }^{\circ} \mathrm{C} / \mathrm{min}$ and then to $310^{\circ} \mathrm{C}$ at $5^{\circ} \mathrm{C} / \mathrm{min}$. Retention times of individual FAME were compared to those of commercial and laboratory standards. Peaks were quantified with Agilent Technologies ChemStation software (Palo Alto, CA, USA).

GC-mass spectrometry (GC-MS) analysis of FAME was performed to confirm individual component identifications and was carried out on a ThermoScientific 1310 GC coupled with a TSQ triple quadruple. Samples were injected using a Tripleplus RSH auto sampler with analyses performed using a non-polar HP-5 Ultra 2 bonded-phase column (50 $\mathrm{m} \times$ $0.32 \mathrm{~mm}$ i.d. $\times 0.17 \mu \mathrm{m}$ film thickness). The HP-5 column was of very similar polarity to the column used for the GC analyses. The initial oven temperature of $45^{\circ} \mathrm{C}$ was held for $1 \mathrm{~min}$, followed by an increase in temperature of $30^{\circ} \mathrm{C}$ per minute to $140{ }^{\circ} \mathrm{C}$, then at $3{ }^{\circ} \mathrm{C}$ per minute to $310{ }^{\circ} \mathrm{C}$, where it was held for 12 minutes. Helium (He) was used as the carrier gas. The operating conditions of the GC-MS were as follows: electron impact energy $70 \mathrm{eV}$; emission current $250 \mu \mathrm{mp}$, transfer line $310{ }^{\circ} \mathrm{C}$; source temperature $240{ }^{\circ} \mathrm{C}$; 
scan rate $0.8 \mathrm{scan} / \mathrm{sec}$ and mass range 40 to $650 \mathrm{Da}$. Thermo Scientific XcaliburTM software (Waltham, MA, USA) was used to acquire and process mass spectra.

\section{Results}

\subsection{The Lipid and Fatty Acid Profiles of 10 Microalgal Species}

To investigate the suitability of microalgae for shrimp larviculture, we cultured all of the 10 selected species under the most commonly used local culture conditions (generally at a higher temperature than used in temperate aquaculture operations) for an incubation period of around 14 days depending on their growth rates. The results in Table 2 indicated the lipid content and percentages of the most abundant FAs in the 10 microalgal species.

Generally, the lipid content obtained in the 10 microalgal species ranged from 16 to $90 \mathrm{mg} / \mathrm{g}$ (dry weight). The Haptophytes, Tisochrysis lutea and Isochrysis galbana, displayed the highest lipid content at 90.3 and $61.1 \mathrm{mg} / \mathrm{g}$, respectively. They were followed by the Eustigmatophyte, Nannochloropsis oceanica, containing total lipids at $55 \mathrm{mg} / \mathrm{g}$. The lowest lipid content was found in the marine diatoms, especially in both species of Thalassiosira weissflogii and T. pseudonana, at $16 \mathrm{mg} / \mathrm{g}$. Polar lipids were the main lipid class ranging from 87.2 to $97.3 \%$ total lipids in most of the studied microalgae. The results also showed that triacylglycerol was detected in all 10 microalgal species, ranging from 0.01 to $2.5 \%$ total lipids. Table 2 shows that the most common FA found in the 10 microalgae were those containing $16(\mathrm{C} 16)$ and $18(\mathrm{C} 18)$ carbon atoms that comprised from 50 to $70 \%$ of the TFA. The long-chain fatty acids $(\geq \mathrm{C} 20, \mathrm{LC})$ were found in all 10 microalgal species, although generally with a low proportion of C22 FA. All C20 fatty acids found in this study were PUFA. The proportions of C20 FA were extremely low (less than 1\% TFA) in the Coccolithophyceae, T. lutea and I. galbana. Both flagellated Coccolithophyceae are characterized with relatively high 18:4w3 (15-21\% TFA) and C22 such as DHA 22:6w3 (ranging from $10-11 \%$ ).

In contrast, the Bacillariophyceae and Coscinodiscophyceae diatoms and the Eustigmatophyte displayed a high capacity of C20 FA accumulation (especially 20:5 $\omega 3$ ). For example, the C20 PUFA of Nannochloropsis oceanica, Phaeodactylum tricornutum, and Cylindrotheca closterium constituted over $30 \%$ of the TFA. Moreover, the SFA were found in this study to mostly include 14:0 (myristic acid), 16:0 (palmitic acid), and 18:0 (stearic acid). The percentage of SFA was less variable among the microalgal species, ranging from 16.5 to $31.3 \%$ of TFA (Table 2). The PUFA were found in all microalgae at relatively high levels. In some diatoms, such as Thalassiosira weissflogii and C. closterium, the percentage of PUFA reached 54.5 and $53.8 \%$ of the TFA, respectively. The lowest proportion of PUFA was found in the marine diatom Chaetoceros muelleri, which was $35.1 \%$ of the TFA (Table 2). The EPA and DHA have been found in most of the selected microalgal species and are recognized as crucial markers for algal strain selection in the application of live feed for aquatic animals. In particular, the microalgae, for example, $N$. oceanica, showed an extremely high proportion of EPA at $30 \%$ of the TFA, and a trace amount of DHA (at $<0.01 \%$ of the TFA). In contrast, while the two Haptophytes T. lutea, and I. galbana displayed a low accumulation capacity for EPA, they produced much higher DHA than all other species, thereby contributing to a high proportion of total PUFA. Lastly, Phaeodactylum tricornutum, Cylindrotheca closterium, and Nannochloropsis oceanica contained the highest relative levels of $\omega-3$ LC -PUFA in cells, which were about $30 \%$ of the TFA (Table 2).

\subsection{The Effect of Temperature on Fatty Acid Profiles in 10 Microalgal Species}

The investigation of the effect of temperature on FA composition of the 10 microalgae was conducted via a separate experiment at 3 temperatures: 20,25 , and $30^{\circ} \mathrm{C}$. The results showed that temperature strongly influenced FA composition in all species. More specifically, the degree of SFA in TFA was higher at $30^{\circ} \mathrm{C}$. This pattern occurred in almost all treatments of the microalgae (Figure 1). The only exception was the marine flagellate Isochrysis galbana, in which the SFA proportion was the highest at $43.0 \%$ of TFA in the middle temperature of $25^{\circ} \mathrm{C}$ compared to $28.7 \%$ at $20^{\circ} \mathrm{C}$ and $31.9 \%$ at $30{ }^{\circ} \mathrm{C}$. 


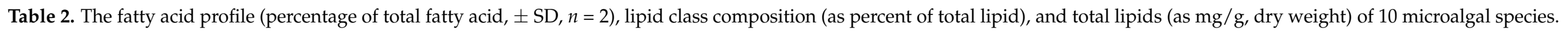

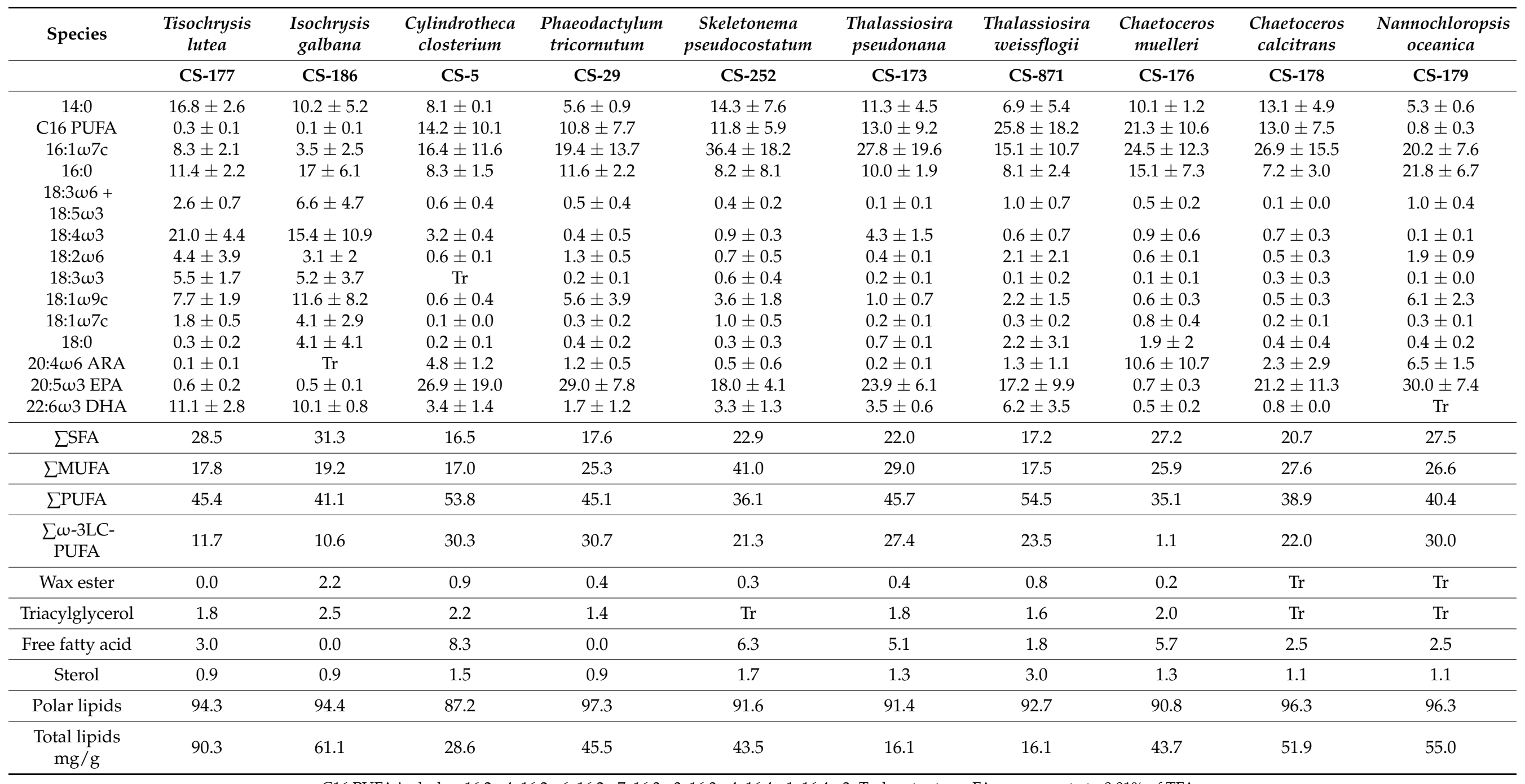

C16 PUFA includes: 16:2 $\omega 4,16: 2 \omega 6,16: 2 \omega 7,16: 3 \omega 3,16: 3 \omega 4,16: 4 \omega 1,16: 4 \omega 3$. Tr denotes trace FA component at $<0.01 \%$ of TFA. 


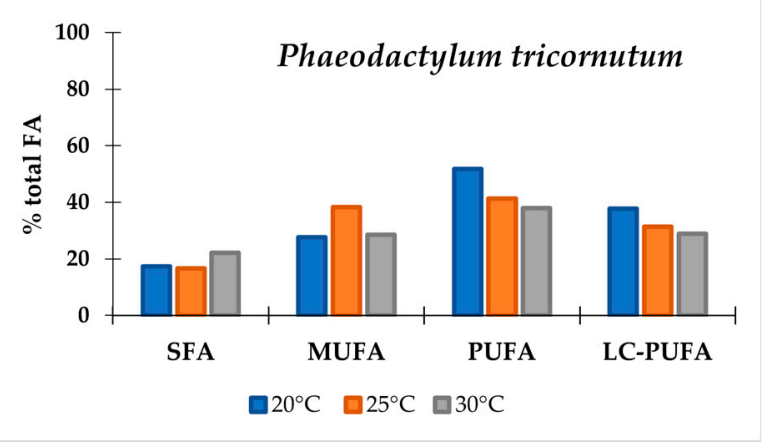

(a)

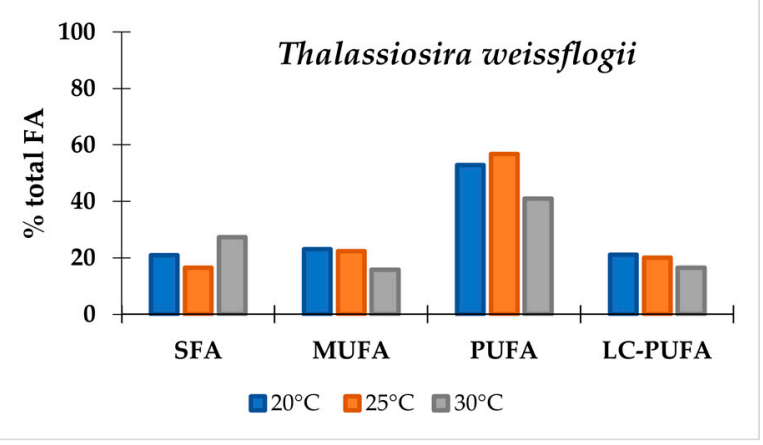

(c)

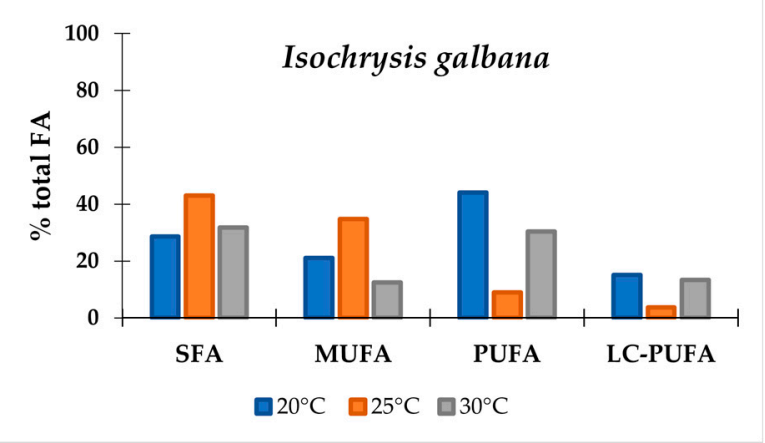

(e)

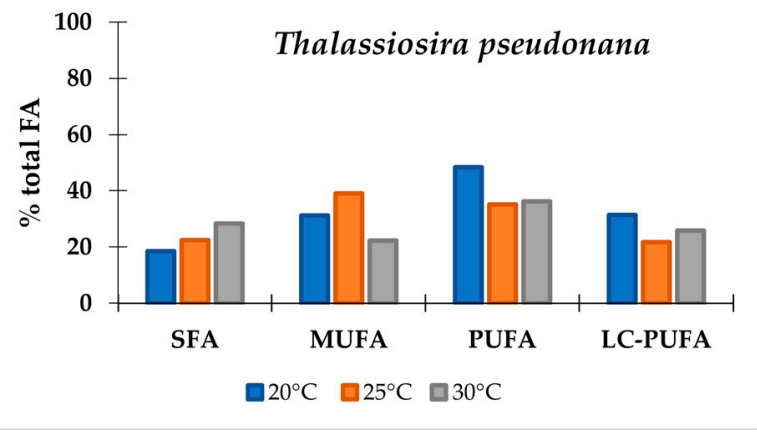

(b)

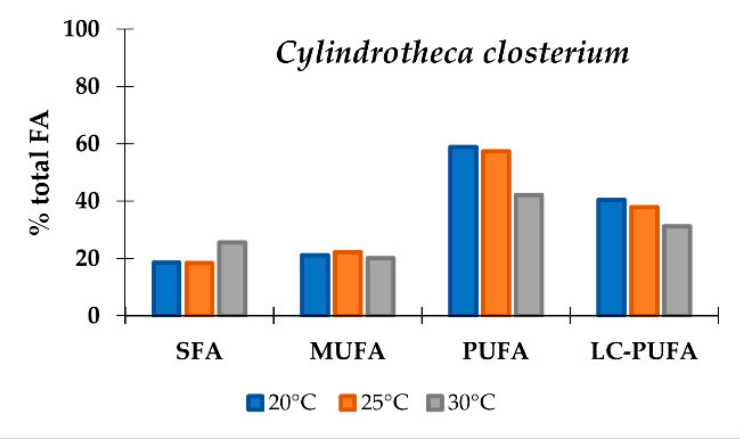

(d)

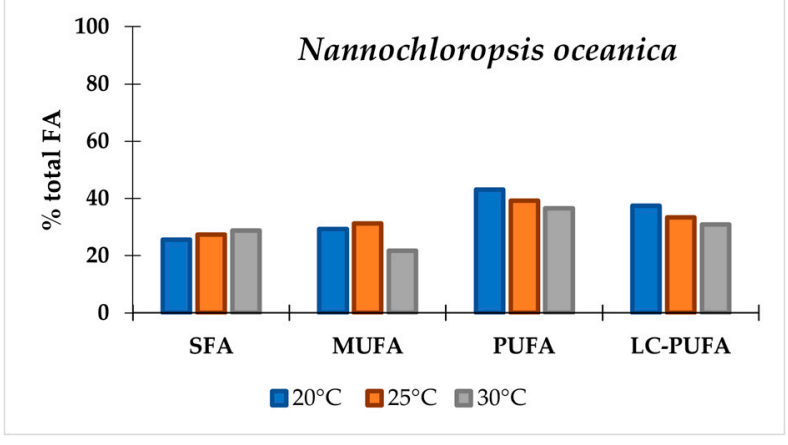

(f)

Figure 1. The groups of fatty acids present at various temperatures. (a) Phaeodactylum tricornutum, (b) Thalasiosira pseudonana, (c) Thalassiosira weissflogii, (d) Cylindrotheca closterium, (e) Isochrysis galbana, and (f) Nannochloropsis oceanica.

In addition, the MUFA proportion was higher at $25^{\circ} \mathrm{C}$ for 6 out of the 10 examined microalgal species, including P. tricornutum, T. pseudonana, T. weissflogii, N. oceanica, I. galbana, and Cylindrotheca closterium (Figure 1). High levels of MUFA were only observed at $20{ }^{\circ} \mathrm{C}$ in Skeletonema pseudocostatum and Chaetoceros muelleri. Secondly, the growth at $30^{\circ} \mathrm{C}$ resulted in a greater proportion of MUFA in Tisochrysis lutea.

The lower temperature of $20^{\circ} \mathrm{C}$ regulated the high capacity of PUFA accumulation, including LC-PUFA such as EPA and DHA, in almost microalgae in this study (Figure 1). 
There were some exceptions revealed in some species, such as T. weissflogii, S. pseudocostatum, and C. muelleri, in which the higher percentage of PUFA in the TFA was found in the culture condition of $25^{\circ} \mathrm{C}$.

\section{Discussion}

In addition to proteins, amino acids, carbohydrates, vitamins, pigments, and sterols, the FA content and composition are key controlling factors in the selection of optimized microalgae species for shrimp larval cultivation $[27,28]$. Moreover, the $\omega 3$ LC-PUFA, especially EPA and DHA, are well known as essential regulators for shrimp larval growth and development [15,27-29]. Glencross (2009) reported that the FA composition of the diet also has a considerable effect on the digestibility of neutral lipids within the diet and concluded that the SFAs 14:0, 16:0, and 18:0 are the least digestible and LC-PUFA (arachidonic acid, ARA-20:4w6, EPA, and DHA) are the most digestible of the fatty acids [14]. The digestibility of specific FAs increases as chain length decreases and also as the level of unsaturation of the FA chain increases in crustaceans, due to the lack of bile salts and underdeveloped lipid digestive capability that produce emulsifiers [14]. Therefore, these species will be promising to provide high proportions of dietary phospholipids that can improve the emulsification potential in the digestive tract. Hence, the digestibility of neutral lipids by crustaceans can be enhanced.

These results were similar to results provided in previous studies [19,30,31]. In our study, the stearidonic acid level of I. galbana was relatively high at $15.4 \%$ of TFA, which is in the same range as in some previous studies, such as (17.7\%) [31] and (12.5\%) [30], but lower than reported in one other study (17.6-25.8\% [27]). This proportion of 18:4w3 was the highest in the taxonomically closely related species of T. lutea at $21.01 \%$ TFA. Another essential PUFA found in both these microalgae was DHA, with relatively high percentages at $10.1 \%$ (I. galbana) and $11.1 \%$ (T. lutea). These results were also very similar to those reported in previous studies (14.1-15.8\% TFA) described by Fidalgo (1998) [32] and Patil (2007) [30]. In this study, the total PUFA and LC-PUFA levels of T. lutea CS-177 were $45.4 \%$ and $11.1 \%$ of the TFA, which were much lower than one earlier study examining different nutrient sources using a clone of the same strain (CCMP1324 reported as I. galbana prior to reidentification as T. lutea: PUFA at $61.1-62.3 \%$ and LC-PUFA at $43.4-46.9 \%$ TFA) [31,32] but similar to values achieved in another study [30] using a different strain with PUFA at $39.9 \%$ and LC-PUFA at $16.6 \%$ TFA.

In our study, the oleaginous microalga N. oceanica displayed EPA, palmitic acid, and palmitoleic acid $(16: 1 \omega 7 \mathrm{c})$ levels at $29.99 \%, 21.78 \%$, and $20.22 \%$ of the TFA, respectively. This level of EPA was similar to that reported in [30] $(23.4 \%)$. Other studies $[33,34]$ indicated a lower range of EPA occurring in N. oceanica, from 1.16 to $10.12 \%$ of the TFA, depending on the culture medium. Consequently, the total PUFA and LC-PUFA levels of $N$. oceanica were high at $40.4 \%$, and $30.0 \%$ of TFA in this study, respectively. The presence of DHA at a low level of around $2 \%$ of the TFA in this species has been reported [34], with our results also consistent with prior reports $[35,36]$ of zero or trace only amounts of DHA in the microalgal class Eustigmatophyceae, including Nannochloropsis.

The FA profile of Bacillariophyceae has been examined in many previous studies [37-43]. In our study, the major fatty acids of the diatoms were myristic acid (14:0), palmitic acid (16:0), palmitoleic acid (16:1 $\omega 7$-cis), EPA, and DHA. Myristic and palmitic acid were the main SFAs in all the tested microalgal species. The results from our study indicated that the SFA levels of the diatoms were in the range $16.5 \%$ (in C. closterium) to $27.2 \%$ TFA (in C. muelleri). These results were similar to many previous studies, for example, the total SFA of P. tricornutum was $27.6 \%$ TFA [30], of Thalassiosira sp. was $27.3 \%$, and of Cylindrotheca sp. was $22.2 \%$ [44]. Palmitoleic acid was the most abundant FA in some diatoms in this study, including in S. pseudocostatum (36.4\% TFA), T. pseudonana (27.7\%), C. calcitrans (26.9\%), and C. muelleri (24.5\% TFA). The profile of T. pseudonana provided by Brown et al. (1996) also showed a similar result for palmitoleic acid in a range from 12.6 to 29.7\% TFA [45]. Moreover, the EPA and DHA proportion was high in most diatoms in this study, except for 
C. muelleri, where EPA and DHA were present at only 0.7 and $0.5 \%$ of the TFA, respectively. These results for C. muelleri were similar to a previous study [43], however, they were much lower than those in the study by Brown et al. (1996) [45]. Chaetoceros is a morphologically diverse genus, but in this study, we chose the two relatively similar species $C$. muelleri and $C$. calcitrans as they are both frequently used in aquaculture. The PUFA variation between these species shows that, despite broad characterization at the class level, there can be important biochemical diversity within a single genus. It is known that $C$. calcitrans is more susceptible to culture failure compared with the more resilient C. muelleri (Australian National Algae Culture Collection-Supply Service), so, while biochemistry is critically important to species selection, other factors play into optimizing actual strain deployment.

An extremely high percentage of EPA in the TFA from 17.2 to $29 \%$ was revealed in some diatoms such as P. tricornutum, T. pseudonana, T. weissflogii, and C. closterium. Jarunan Pratoomyot et al. reported that the EPA proportion of Nitzschia cf. ovalis was $26.7 \%$ and Thalassiosira sp. was $16.7 \%$ of the TFA [44]. In addition, two further studies indicated that P. tricornutum maintained an EPA percentage of around 22.8-30.7\% of the TFA [43,46]. Lastly, Brown et al. (1996) stated the EPA level of T. pseudonana was $17.5-32.7 \%$ of the TFA [45]. Interestingly, aside from the high cellular EPA levels in these four diatom species, they also displayed DHA at levels between 1.7 and $6.2 \%$. This results in the notably high total PUFA levels and resultant positive consideration of these microalgae for larval prawn production.

The lipid content and FA composition vary greatly with species and specific culture conditions [8,9,46-49]. With respect to environmental factors which influence the FA profile of microalgae, the nutrient form, salinity, light, and temperature have all been considered to be key determinants [46,50-52]. In this study, the SFA proportion was highest under the high temperature of $30^{\circ} \mathrm{C}$ in 9 of the 10 tested microalgae. These results were similar to several previous studies which have described increased SFA and MUFA proportions under increasing temperatures [46,53-55]. In addition, most microalgae examined in the present study also followed a pattern of increased proportion of PUFA with decreasing growth temperatures. In contrast to the manipulation of single environmental variables, the effect of temperature and light combined has shown no clear trends [46,50-52]. Most of the selected species are temperate microalgae, and the physiological change and logistical energy cost of adapting to tropical growth conditions is not fully understood.

This study clearly demonstrated the variation in the FA profiles across 10 microalgal species. Both Coccolithophyceae species, T. lutea and I. galbana, are characterised with high lipid-producing potential and fatty acid distribution with high 18:4w3 and C22 such as DHA 22:6w3 and less C20 PUFA. All Bacillariophyceae and Coscinodiscophyceae have compositions typical of other diatoms with low C18 and C22 but high C20 PUFA

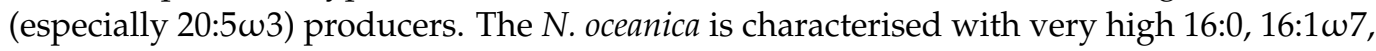
and 20:5 $\omega 3$ trace level ( $<0.01 \%$ of TFA) of C22 PUFA detected, which is typical of other reports for eustigmatophytes. The study also indicates that SFA and MUFA were increased and PUFA was decreased with increasing growth temperatures from $20{ }^{\circ} \mathrm{C}$ to $30{ }^{\circ} \mathrm{C}$, with the latter higher temperature pertinent to Vietnamese production systems. Future research will evaluate the growth and survival of shrimp postlarvae and include targeting microalgae, including endemic Vietnamese strains with high PUFA yield with different growth parameters examined in order to optimise the quantity and quality of the biomass and oil yield. The inclusion of proximate analysis can also enhance our understanding of specific dietary requirements during shrimp postlarvae production. In turn, such research and development will provide growers with the opportunity to better meet the specific dietary requirements of shrimp postlarvae production in Vietnam. 
Author Contributions: Conceptualization, K.J.L.-C. and T.H.; methodology, K.J.L.-C. and I.D.J.; validation, T.D.M. and N.B.A.C.; formal analysis, K.J.L.-C. and T.D.M.; investigation, T.D.M.; resources, K.J.L.-C., T.H. and I.D.J.; data curation, K.J.L.-C. and I.D.J.; writing-original draft preparation, T.D.M.; writing-review and editing, K.J.L.-C.; visualization, I.D.J.; supervision, H.Q.P. and N.B.A.C.; project administration, T.H.; funding acquisition reviewing draft. All authors have read and agreed to the published version of the manuscript.

Funding: This research was funded in part by Minh Phu Seafood Corporation.

Institutional Review Board Statement: Not applicable.

Data Availability Statement: The data presented in this study are available on request from the corresponding author. The data are not publicly available due to commercial restrictions.

Acknowledgments: The authors thank the Commonwealth Scientific and Industrial Research Organisation (CSIRO), Australian National Algae Culture Collection and Minh Phu Seafood Corporation for their support of the project, Mina Brock for lipid analysis, Cathy Johnston and Ros Watson for assistance during sample preparation and cooperation, Peter Nichols for comments on an earlier version of this manuscript, and three anonymous journal reviewers for their helpful inputs.

Conflicts of Interest: The authors declare no conflict of interest. This study was funded partly by Minh Phu Seafood Corporation, who produces and exports shrimp products. Dr. Ngoc Bao Anh Cai is the Director of Research and Development at Minh Phu Seafood Corporation and the company had no role in the design of the study, in the collection, analyses, or interpretation of data, or in the decision to publish the results.

\section{Appendix A}
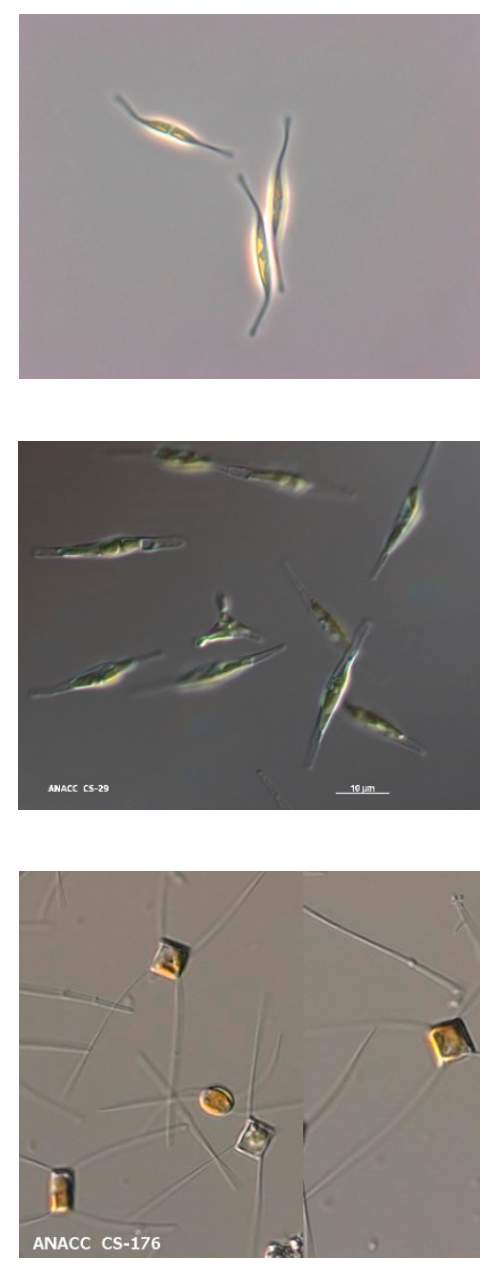

Figure A1. Cont. 


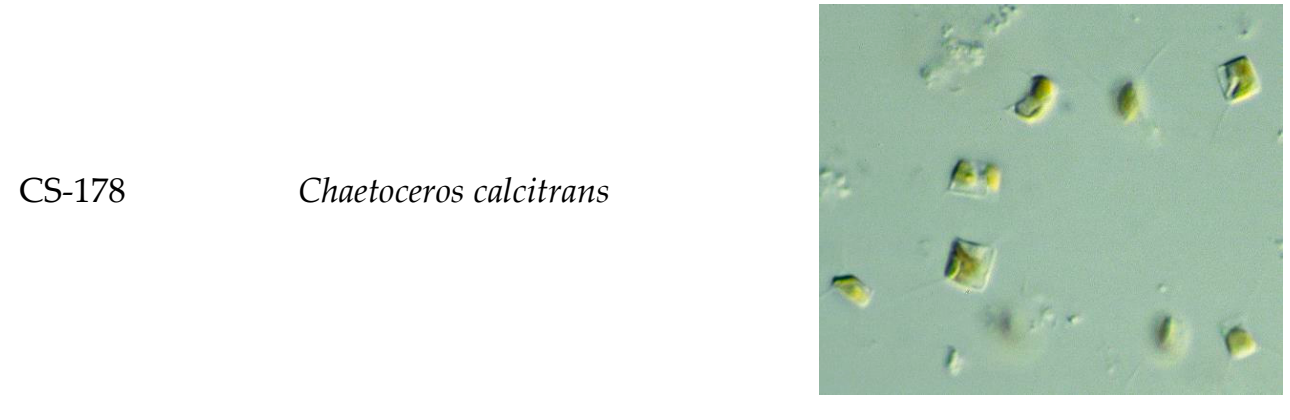

CS-252 Skeletonema pseudocostatum

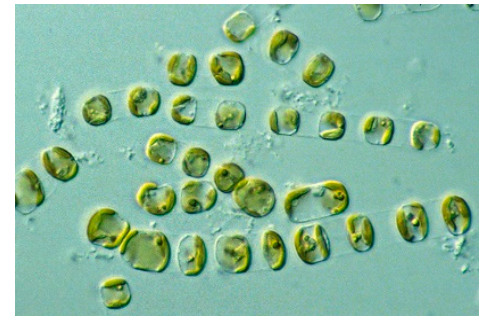

CS-173

Thalassiosira pseudonana

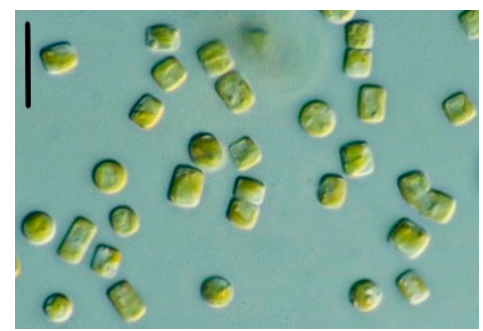

CS-871

Thalassiosira weissflogii

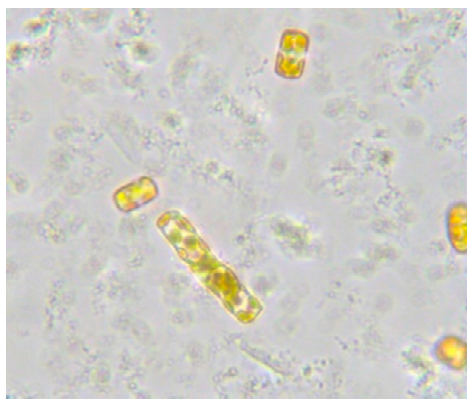

CS-186

Isochrysis galbana

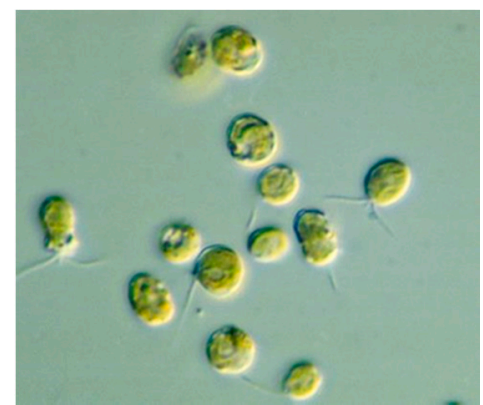

Figure A1. Cont. 
CS-177

Tisochrysis lutea

CS-179
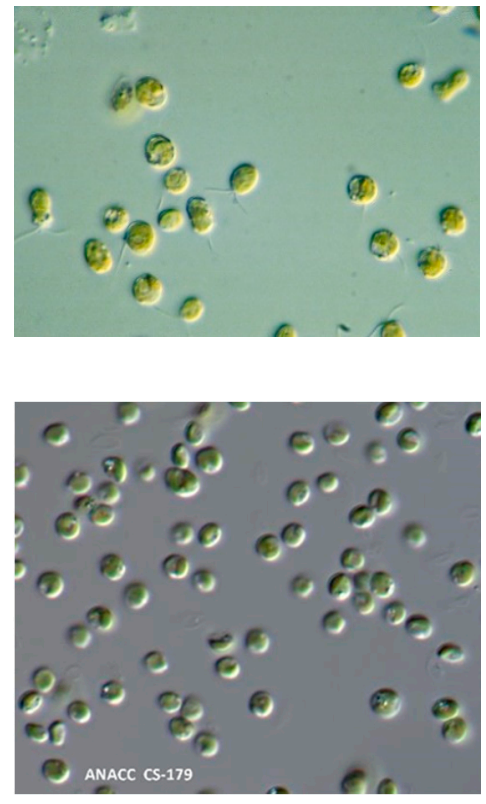

Figure A1. Micrographs of microalgae reproduced with the permission of the ANACC from a "Microalgae for Mariculture" guide.

\section{References}

1. Lembi, C.A.; Waaland, J.R. Algae and Human Affairs; Cambridge University Press: Cambridge, UK, 1988; pp. 5-22.

2. Metting, F. Biodiversity and application of microalgae. J. Ind. Microbiol. 1996, 17, 477-489. [CrossRef]

3. Apt, K.E.; Behrens, P.W. Commercial developments in microalgal biotechnology. J. Phycol. 1999, 35, 215-226. [CrossRef]

4. Ariede, M.B.; Candido, T.M.; Jacome, A.L.M.; Velasco, M.V.R.; de Carvalho, J.C.M.; Baby, A.R. Cosmetic attributes of algae-A review. Algal Res. 2017, 25, 483-487. [CrossRef]

5. Priyadarshani, I.; Rath, B. Commercial and industrial applications of micro algae-A review. J. Algal Biomass Util. 2012, 3, 89-100.

6. Mehariya, S.; Goswami, R.K.; Verma, P.; Lavecchia, R.; Zuorro, A. Integrated approach for wastewater treatment and biofuel production in microalgae biorefineries. Energies 2021, 14, 2282. [CrossRef]

7. Zullaikah, S.; Utomo, A.T.; Yasmin, M.; Ong, L.K.; Ju, Y.H. Ecofuel conversion technology of inedible lipid feedstocks to renewable fuel. In Advances in Eco-Fuels for a Sustainable Environment; Elsevier: Amsterdam, The Netherlands, 2019; pp. 237-276.

8. Salama, E.-S.; Kurade, M.B.; Abou-Shanab, R.A.; El-Dalatony, M.M.; Yang, I.-S.; Min, B.; Jeon, B.-H. Recent progress in microalgal biomass production coupled with wastewater treatment for biofuel generation. Renew. Sustain. Energy Rev. 2017, 79, 1189-1211. [CrossRef]

9. D'Alessandro, E.B.; Antoniosi Filho, N.R. Concepts and studies on lipid and pigments of microalgae: A review. Renew. Sustain. Energy Rev. 2016, 58, 832-841. [CrossRef]

10. Demirbas, A. Use of algae as biofuel sources. Energy Convers. Manag. 2010, 51, 2738-2749. [CrossRef]

11. Tam, L.T.; Van Cong, N.; Ha, N.C.; Hang, N.T.M.; Van Minh, C.; Hong, D.D. Cultivation and biomass production of the diatom Thalassiosira weissflogii as a live feed for white-leg shrimp in hatcheries and commercial farms in Vietnam. J. Appl. Phycol. 2021, 33, 1559-1577. [CrossRef]

12. Deshmukh, S.; Kumar, R.; Bala, K. Microalgae biodiesel: A review on oil extraction, fatty acid composition, properties and effect on engine performance and emissions. Fuel Process. Technol. 2019, 191, 232-247. [CrossRef]

13. Kandathil Radhakrishnan, D.; AkbarAli, I.; Schmidt, B.V.; John, E.M.; Sivanpillai, S.; Thazhakot Vasunambesan, S. Improvement of nutritional quality of live feed for aquaculture: An overview. Aquac. Res. 2020, 51, 1-17. [CrossRef]

14. Glencross, B.D. Exploring the nutritional demand for essential fatty acids by aquaculture species. Rev. Aquac. 2009, 1, 71-124. [CrossRef]

15. Figueiredo, J.; Lin, J.; Anto, J.; Narciso, L. The consumption of DHA during embryogenesis as an indicative of the need to supply DHA during early larval development: A review. J. Aquac. Res. Dev. 2012, 3, 1-7. [CrossRef]

16. Anger, K. Patterns of growth and chemical composition in decapod crustacean larvae. Invertebr. Reprod. Dev. 1998, 33, 159-176. [CrossRef]

17. Harrison, K.E. The role of nutrition in maturation, reproduction and embryonic development of decapod crustacean: A review. J. Shellfish Res. 1990, 9, 1-28.

18. Hubbs, C.; Blaxter, J. Ninth larval fish conference: Development of sense organs and behaviour of Teleost larvae with special reference to feeding and predator avoidance. Trans. Am. Fish. Soc. 1986, 115, 98-114. [CrossRef] 
19. Griffiths, M.J.; van Hille, R.P.; Harrison, S.T. Lipid productivity, settling potential and fatty acid profile of 11 microalgal species grown under nitrogen replete and limited conditions. J. Appl. Phycol. 2012, 24, 989-1001. [CrossRef]

20. Volkman, J. Sterols in microorganisms. Appl. Microbiol. Biotechnol. 2003, 60, 495-506. [CrossRef]

21. Huu, N. Personal Communication; Directorate of Fisheries: Hanoi, Vietnam, 2019.

22. Ngoc, Q.T.K.; Xuan, B.B.; Sandorf, E.D.; Phong, T.N.; Trung, L.C.; Hien, T.T. Willingness to adopt improved shrimp aquaculture practices in Vietnam. Aquac. Econ. Manag. 2021, 1-24. [CrossRef]

23. Hai, T.N.; Duc, P.M.; Son, V.N.; Minh, T.H.; Phuong, N.T. Innovation in seed production and farming of marine shrimp in Vietnam. World Aquac. 2015, 46, 32-37.

24. Bligh, E.G.; Dyer, W.J. A rapid method of total lipid extraction and purification. Can. J. Biochem. Physiol. 1959, 37, 911-917. [CrossRef]

25. Bakes, M.J.; Nichols, P.D. Lipid, fatty acid and squalene composition of liver oil from six species of deep-sea sharks collected in southern Australian waters. Comp. Biochem. Physiol. Part B Biochem. Mol. Biol. 1995, 110, 267-275. [CrossRef]

26. Chang, K.J.L.; Mansour, M.P.; Dunstan, G.A.; Blackburn, S.I.; Koutoulis, A.; Nichols, P.D. Odd-chain polyunsaturated fatty acids in thraustochytrids. Phytochemistry 2011, 72, 1460-1465. [CrossRef]

27. Huerlimann, R.; De Nys, R.; Heimann, K. Growth, lipid content, productivity, and fatty acid composition of tropical microalgae for scale-up production. Biotechnol. Bioeng. 2010, 107, 245-257. [CrossRef] [PubMed]

28. Martínez-Fernández, E.; Acosta-Salmón, H.; Southgate, P.C. The nutritional value of seven species of tropical microalgae for black-lip pearl oyster (Pinctada margaritifera, L.) larvae. Aquaculture 2006, 257, 491-503. [CrossRef]

29. Sargent, J.; McEvoy, L.; Bell, J. Requirements, presentation and sources of polyunsaturated fatty acids in marine fish larval feeds. Aquaculture 1997, 155, 117-127. [CrossRef]

30. Patil, V.; Källqvist, T.; Olsen, E.; Vogt, G.; Gislerød, H.R. Fatty acid composition of 12 microalgae for possible use in aquaculture feed. Aquac. Int. 2007, 15, 1-9. [CrossRef]

31. Lin, Y.-H.; Chang, F.-L.; Tsao, C.-Y.; Leu, J.-Y. Influence of growth phase and nutrient source on fatty acid composition of Isochrysis galbana CCMP 1324 in a batch photoreactor. Biochem. Eng. J. 2007, 37, 166-176. [CrossRef]

32. Fidalgo, J.; Cid, A.; Torres, E.; Sukenik, A.; Herrero, C. Effects of nitrogen source and growth phase on proximate biochemical composition, lipid classes and fatty acid profile of the marine microalga Isochrysis galbana. Aquaculture 1998, 166, 105-116. [CrossRef]

33. Savvidou, M.G.; Boli, E.; Logothetis, D.; Lymperopoulou, T.; Ferraro, A.; Louli, V.; Mamma, D.; Kekos, D.; Magoulas, K.; Kolisis, F.N. A study on the effect of macro-and micro-nutrients on Nannochloropsis oceanica growth, fatty acid composition and magnetic harvesting efficiency. Plants 2020, 9, 660. [CrossRef]

34. Sirisuk, P.; Sunwoo, I.; Kim, S.H.; Awah, C.C.; Ra, C.H.; Kim, J.-M.; Jeong, G.-T.; Kim, S.-K. Enhancement of biomass, lipids, and polyunsaturated fatty acid (PUFA) production in Nannochloropsis oceanica with a combination of single wavelength light emitting diodes (LEDs) and low temperature in a three-phase culture system. Bioresour. Technol. 2018, 270, 504-511. [CrossRef]

35. Mitani, E.; Nakayama, F.; Matsuwaki, I.; Ichi, I.; Kawabata, A.; Kawachi, M.; Kato, M. Fatty acid composition profiles of 235 strains of three microalgal divisions within the NIES Microbial Culture Collection. Microb. Resour. Syst 2017, $33,1929$.

36. Volkman, J.K.; Brown, M.R.; Dunstan, G.A.; Jeffrey, S. The biochemical composition of marine microalgae from the class Eustigmatophyceae 1. J. Phycol. 1993, 29, 69-78. [CrossRef]

37. Marella, T.K.; Tiwari, A. Marine diatom Thalassiosira weissflogii based biorefinery for co-production of eicosapentaenoic acid and fucoxanthin. Bioresour. Technol. 2020, 307, 123245. [CrossRef]

38. Vella, F.M.; Sardo, A.; Gallo, C.; Landi, S.; Fontana, A.; d'Ippolito, G. Annual outdoor cultivation of the diatom Thalassiosira weissflogii: Productivity, limits and perspectives. Algal Res. 2019, 42, 101553. [CrossRef]

39. Sahin, M.S.; Khazi, M.I.; Demirel, Z.; Dalay, M.C. Variation in growth, fucoxanthin, fatty acids profile and lipid content of marine diatoms Nitzschia sp. and Nanofrustulum shiloi in response to nitrogen and iron. Biocatal. Agric. Biotechnol. 2019, 17, 390-398. [CrossRef]

40. Lou, Y.; Liu, Y.; Wang, H.; Li, N.; Liu, Q.; Liu, Y.; Zhao, X. Effects of CO2 restriction on growth of Nitzschia closterium: Evidence from stable isotopes and fatty acids. Ecotoxicol. Environ. Saf. 2019, 177, 7-17. [CrossRef] [PubMed]

41. Lin, Q.; Zhuo, W.-H.; Wang, X.-W.; Chen, C.-P.; Gao, Y.-H.; Liang, J.-R. Effects of fundamental nutrient stresses on the lipid accumulation profiles in two diatom species Thalassiosira weissflogii and Chaetoceros muelleri. Bioprocess Biosyst. Eng. 2018, 41, 1213-1224. [CrossRef] [PubMed]

42. Renaud, S.M.; Thinh, L.-V.; Parry, D.L. The gross chemical composition and fatty acid composition of 18 species of tropical Australian microalgae for possible use in mariculture. Aquaculture 1999, 170, 147-159. [CrossRef]

43. Zhukova, N.V.; Aizdaicher, N.A. Fatty acid composition of 15 species of marine microalgae. Phytochemistry 1995, 39, 351-356. [CrossRef]

44. Pratoomyot, J.; Srivilas, P.; Noiraksar, T. Fatty acids composition of 10 microalgal species. Songklanakarin J. Sci. Technol 2005, 27, 1179-1187.

45. Brown, M.R.; Dunstan, G.A.; Norwood, S.J.; Miller, K.A. Effects of harvest stage and light on the biochemical composition of the diatom Thalassiosira pseudonana 1. J. Phycol. 1996, 32, 64-73. [CrossRef]

46. Qiao, H.; Cong, C.; Sun, C.; Li, B.; Wang, J.; Zhang, L. Effect of culture conditions on growth, fatty acid composition and DHA/EPA ratio of Phaeodactylum tricornutum. Aquaculture 2016, 452, 311-317. [CrossRef] 
47. Chang, K.S.; Kim, J.; Park, H.; Hong, S.-J.; Lee, C.-G.; Jin, E. Enhanced lipid productivity in AGP knockout marine microalga Tetraselmis sp. using a DNA-free CRISPR-Cas9 RNP method. Bioresour. Technol. 2020, 303, 122932. [CrossRef] [PubMed]

48. Suresh, K.S.; Suresh, P.; Kudre, T.G. Prospective ecofuel feedstocks for sustainable production. In Advances in Eco-Fuels for a Sustainable Environment; Elsevier: Amsterdam, The Netherlands, 2019; pp. 89-117.

49. Gatamaneni, B.L.; Orsat, V.; Lefsrud, M. Factors affecting growth of various microalgal species. Environ. Eng. Sci. 2018, 35, 1037-1048. [CrossRef]

50. Indrayani, I.; Moheimani, N.R.; de Boer, K.; Bahri, P.A.; Borowitzka, M.A. Temperature and salinity effects on growth and fatty acid composition of a halophilic diatom, Amphora sp. MUR258 (Bacillariophyceae). J. Appl. Phycol. 2020, 32, 977-987. [CrossRef]

51. Chaisutyakorn, P.; Praiboon, J.; Kaewsuralikhit, C. The effect of temperature on growth and lipid and fatty acid composition on marine microalgae used for biodiesel production. J. Appl. Phycol. 2018, 30, 37-45.

52. Aussant, J.; Guihéneuf, F.; Stengel, D.B. Impact of temperature on fatty acid composition and nutritional value in eight species of microalgae. Appl. Microbiol. Biotechnol. 2018, 102, 5279-5297. [CrossRef] [PubMed]

53. Renaud, S.M.; Thinh, L.-V.; Lambrinidis, G.; Parry, D.L. Effect of temperature on growth, chemical composition and fatty acid composition of tropical Australian microalgae grown in batch cultures. Aquaculture 2002, 211, 195-214. [CrossRef]

54. Renaud, S.M.; Zhou, H.; Parry, D.L.; Thinh, L.-V.; Woo, K. Effect of temperature on the growth, total lipid content and fatty acid composition of recently isolated tropical microalgae Isochrysis sp., Nitzschia closterium, Nitzschia paleacea, and commercial species Isochrysis sp.(clone T. ISO). J. Appl. Phycol. 1995, 7, 595-602. [CrossRef]

55. Thompson, P.A.; Guo, M.x.; Harrison, P.J.; Whyte, J.N. Effects of variation in temperature. II. On the fatty acid composition of eight species of marine phytoplankton 1. J. Phycol. 1992, 28, 488-497. 